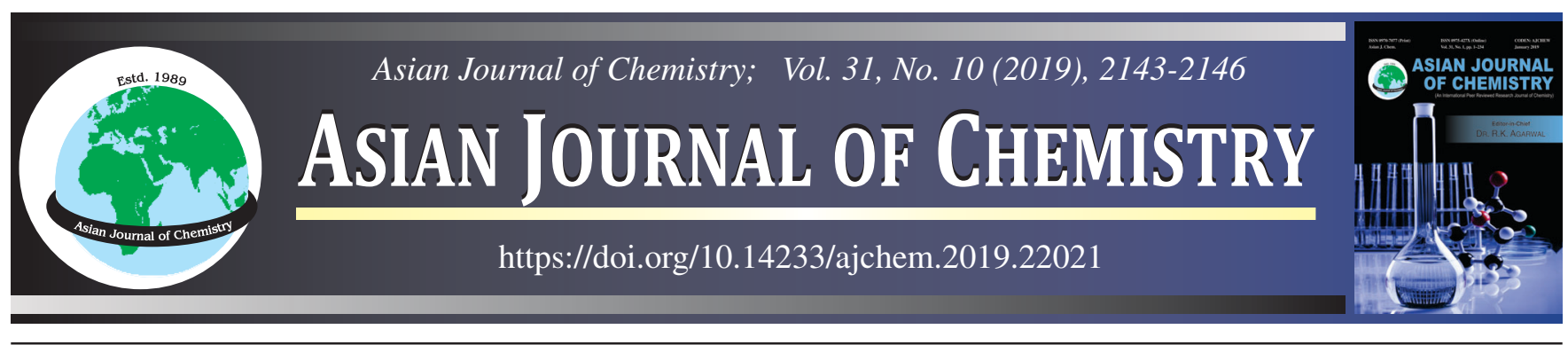

\title{
Monitoring of Organochlorine Pesticides Residues in Five Fruits using Gas Liquid Chromatography Equipped with Electron Capture Detector (GLC-ECD)
}

\author{
Devendra Kumar ${ }^{*}$ and Shiva Sharma
}

Department of Chemistry, Institute of Basic Sciences, Dr. Bhimrao Ambedkar University, Khandari Campus, Agra-282002, India

*Corresponding author: E-mail: devendrakumar131@gmail.com

Received: 22 February 2019 Accepted: 9 April 2019; Published online: 30 August 2019;

India is the largest producer of fruits as they are important part of their economy. But they are badly affected by insect-pest attack during harvesting. Farmers use a large amount of pesticides to protect them but due to their longer persistence they found in fruits in small quantities. This paper described an analytical methodology for the monitoring of 20 organochlorine pesticides in 5 fruits viz. pineapple (Ananas comosus), apple (Malus pumila), plum (Prunus domestica), papaya (Carica papaya) and mango (Mangifera indica) by using gas liquid chromatography equipped with electron capture detector (GLC-ECD). During the monitoring work it has been found that each fruit was contaminated with pesticides. Pineapple was found contaminated with $\beta$-BHC, $\delta$-BHC, heptachlor epoxide, dieldrin, endrin and methoxychlor; apple was found contaminated $\gamma$-BHC, $\delta$-BHC, heptachlor epoxide, dieldrin, endrin, endosulfan II and methoxychlor; plum and papaya were found contaminated with $\gamma$-BHC, $\beta$-BHC, $\delta$-BHC, heptachlor epoxide, 4,4'-DDE, endrin, endosulfan sulfate and methoxychlor; mango was found contaminated with $\beta$-BHC, $\delta$-BHC, 4,4'-DDE, endrin, endosulfan sulfate and methoxychlor. However, the detected concentration of pesticides was below the MRL values but their long term use can cause serious health problems.

Keywords: Organochlorine, Pesticides, Fruits.

ᄂ -------------------------------1

\section{INTRODUCTION}

Fruits are important components of the human diet since they provide essential nutrients, like vitamins and minerals that can help to keep us healthy [1]. In India estimated that per capita fruits availability is around $200.6 \mathrm{~g}$ per day which is below the recommended quantity $230 \mathrm{~g}$ per capita per day [2]. To protect the fruits from the insect-pest attack and to increase the yield, generally, farmers used large amount of chemical pesticides. The worldwide consumption of pesticides is about 2 million tons per year out of which $45 \%$ is used by Europe alone, $25 \%$ is consumed in the USA and $25 \%$ in the rest of the world. India's share is just $3.75 \%$. The usage of pesticides [3] in India is only $0.5 \mathrm{~kg} / \mathrm{ha}$ while in case of Korea and Japan it is 6.6 and $12.0 \mathrm{~kg} / \mathrm{ha}$, respectively. Globally, the pesticides [4] cover only $25 \%$ of the cultivated land area. Amongst the pesticides (total), $\mathrm{HCH}$ (only $\gamma$-HCH is allowed), DDT are most commonly used pesticides which account for $70 \%$ of the consumption of pesticides. These pesticides remain the choice of small farmers because they are cost-effective, easily available and display a wide spectrum of bioactivity [4]. The excessive use of pesticides is of major concern [5]. Pesticides can be acutely toxic and their contamination is a worldwide public health concern and main international trade problem [6]. They can cause harmful or lethal effects after one single episode of ingestion, inhalation or skin contact. The symptoms are evident shortly after exposure or can arise within $48 \mathrm{~h}$ [7]. Pesticides can cause respiratory tract irritation [8], sore throat and/or cough allergic [9] sensitization, eye and skin irritation [10], nausea [8], vomiting [11], diarrhea [10], headache [12], loss of consciousness [13], extreme weakness [14], death [15]. Several studies [16-18] on organochlorine pesticides in different matrices including food commodities have been reported, which indicated that exposure of organochlorine pesticides (OCPs) has been associated with human health risk of gestational diabetes [19], insulin resistance [20], diarrhea [21], skin conditions [22], reproductive problem [23], depression [24] and cancer [25]. Keeping in view of the above adverse effects on human health it has been decided to monitor the pesticide residue concentration in different fruits. In continuation of our previous work

This is an open access journal, and articles are distributed under the terms of the Attribution 4.0 International (CC BY 4.0) License. This license lets others distribute, remix, tweak, and build upon your work, even commercially, as long as they credit the author for the original creation. You must give appropriate credit, provide a link to the license, and indicate if changes were made. 
[26,27] in this study, we have monitored 20 organochlorine pesticides in pineapple (Ananas comosus), apple (Malus pumila), plum (Prunus domestica), papaya (Carica papaya) and mango (Mangifera indica).

\section{EXPERIMENTAL}

All glassware was thoroughly washed by deionized water and then rinsed with acetone and dried in oven $\left(150{ }^{\circ} \mathrm{C}\right)$ for overnight before use. Solvents like acetone, acetonitrile, ethyl acetate, dichloromethane and hexane were distilled before use. Adsorbents neutral silica gel and charcoal were activated before use. The extracted and purified samples of fruits were analyzed by gas liquid chromatography equipped with capillary columns using $63 \mathrm{Ni}$ electron capture detector (GLC-ECD). Minor equipment such as rotary evaporator, mechanical shaker and waring blender, etc. were also used during extraction. A $2.0 \mu \mathrm{L}$ solution of standard was injected to record the chromatogram of pesticides.

\section{Extraction of pesticides in fruits}

Collection and sample preparation: The samples consisted of $250 \mathrm{~g}$ of each fruits, i.e. pineapple, papaya, apple, plum and mango were collected from local market. Each sample was refrigerated at $5{ }^{\circ} \mathrm{C}$ and analyzed within few days of collection. In order to assess the right concentration of pesticides reaching within human body, household processing like washing, peeling off covering, etc. were carried out. Each fruit was washed for few minutes under tap water and dried with filter paper. After drying, each fruit was chopped into small pieces and a representative sample (250 g) was macerated with $25 \mathrm{~g}$ anhydrous sodium sulfate in waring blender to make a fine paste.

Extraction for pineapple (Ananas comosus): A macerated sample of pineapple $(50 \mathrm{~g})$ was extracted with $100 \mathrm{~mL}$ dichloromethane by using mechanical shaker for $2 \mathrm{~h}$. The extract was passed from the layer of sodium sulfate by using funnel. The filtrate was concentrated under vacuum up to $30-40 \mathrm{~mL}$ and then transferred to a $500 \mathrm{~mL}$ separating funnel. Then aqueous solution of $\mathrm{NaCl}(10 \%, 50 \mathrm{~mL})$ was added and shaken gently for $2 \mathrm{~h}$. The extract was exchanged into ethyl acetate $(3 \times 50$ $\mathrm{mL}$ ) by liquid-liquid partitioning. The organic layer was separated out and again passed through a layer of sodium sulfate ( $5 \mathrm{~g}$ ). The filtrate was evaporated up to dryness $(2-5 \mathrm{~mL})$ in rotary evaporator and dissolved in $10 \mathrm{~mL}$ hexane.

Extraction for apple (Malus pumila), plum (Prunus domestica) and papaya (Carica papaya): A fine paste of each fruit $(50 \mathrm{~g})$ was taken and subjected to extraction with $100 \mathrm{~mL}$ acetone $(3 \times 100 \mathrm{~mL})$. The extract was filter with the help of Buchner funnel. The filtrate was concentrated under vacuum upto $5 \mathrm{~mL}$ and then transferred to a $500 \mathrm{~mL}$ separating funnel. $50 \mathrm{~mL}$ saline water $(2 \%, \mathrm{w} / \mathrm{v})$ was added to it and shake for $50 \mathrm{~min}$. The extract was exchanged in to dichloromethane layer by liquid liquid partitioning $(3 \times 50 \mathrm{~mL})$. The organic layer was separated out from the separating funnel and passed through a layer of sodium sulfate $(5 \mathrm{~g})$. The extract was evaporated to dryness $(2-5 \mathrm{~mL}$ ) by using rotary evaporator. The concentrated extract was redissolved in $10 \mathrm{~mL}$ of $n$-hexane.
Extraction for mango (Mangifera indica): A fine paste $(50 \mathrm{~g})$ was subjected for extraction with $50 \mathrm{~mL}$ acetonitrile-ethyl acetate-hexane $(8: 1: 1 \mathrm{v} / \mathrm{v})$ in a waring blender. The extract was collected by filtration with Buchner funnel. The fruit residue was again subjected for extraction with two times. The collected extract was evaporated under vacuum upto about 5 $\mathrm{mL}$ and transferred to the separating funnel $(500 \mathrm{~mL}) .50 \mathrm{ml}$ saline water $(2 \% \mathrm{w} / \mathrm{v})$ was added and shaken for $30 \mathrm{~min}$. The extract was exchanged into dichloromethane layer by liquidliquid partioning $(3 \times 50 \mathrm{~mL})$. The extract was passed through a layer of sodium sulfate $(5 \mathrm{~g})$ and evaporated to dryness in rotary evaporator. The concentrated extract was dissolved in $10 \mathrm{~mL}$ of hexane-acetone (9:1).

Purification: The collected extracts were subjected for clean up by column packed with silica gel:activated charcoal $(5: 1 \mathrm{w} / \mathrm{w}) / \mathrm{silica}$ gel. Each extract was eluted with $50 \mathrm{~mL}$ of $n$ hexane then subjected to GC-ECD for analysis of pesticides.

\section{RESULTS AND DISCUSSION}

First by running chromatogram of standard of pesticides chosen for monitoring work, a retention time of the peaks for pesticides and their peak areas corresponding to $2.0 \mu \mathrm{g} / \mu \mathrm{L}$ concentration was determined (Table-1).

\begin{tabular}{clccc}
\multicolumn{5}{c}{ TABLE-1 } \\
\multicolumn{5}{c}{$\begin{array}{c}\text { RETENTION TIME AND PEAK AREA OF } \\
\text { ORGANOCHLORINE PESTICIDES OF STANDARD }\end{array}$} \\
\hline Peak & \multicolumn{1}{c}{ Pesticides } & Ret. time & Area & Area $(\%)$ \\
\hline 1 & $\alpha$-BHC & 8.481 & 747866 & 0.3123 \\
2 & $\gamma$-BHC & 9.775 & 178423 & 0.0745 \\
3 & $\beta$-BHC & 12.041 & 17788716 & 7.4293 \\
4 & $\delta$-BHC & 13.533 & 23197482 & 9.6882 \\
5 & Heptachlor & 15.042 & 13099995 & 5.4711 \\
6 & Aldrin & 16.753 & 15246076 & 6.3674 \\
7 & Heptachlor epoxide & 18.379 & 15052379 & 6.2865 \\
8 & $\gamma$-Chlordane & 20.223 & 13459524 & 5.6212 \\
9 & $\alpha$-Chlordane & 21.342 & 14431111 & 6.0270 \\
10 & Endosulfan I & 21.925 & 25859986 & 10.8001 \\
11 & $4,4^{\prime}$-DDE & 23.068 & 6975083 & 2.9131 \\
12 & Dieldrin & 23.154 & 18779776 & 7.8432 \\
13 & Endrin & 24.095 & 13244260 & 5.5313 \\
14 & $4,4^{\prime}$-DDD & 24.667 & 12228021 & 5.1069 \\
15 & Endosulfan II & 25.065 & 4210779 & 1.7586 \\
16 & Endrin aldehyde & 25.353 & 8823023 & 3.6848 \\
17 & $4,4^{\prime}$-DDT & 26.463 & 10972013 & 4.5823 \\
18 & Endosulfan sulfate & 26.718 & 8989607 & 3.7544 \\
19 & Methoxychlor & 28.545 & 12990256 & 5.4252 \\
20 & Endrin ketone & 29.325 & 2963671 & 1.2377 \\
\hline
\end{tabular}

In the chromatogram of standard (Fig. 1), the peaks of different isomers of benzene hexachloride (BHC) were found at $\mathrm{R}_{t}$ values $8.481,9.775,12.041$ and 13.533 which correspond to $\alpha$-BHC, $\gamma$-BHC, $\beta$-BHC and $\delta$-BHC, respectively. The peaks of heptachlor and heptachlor epoxide were found at $R_{t}$ value 15.042 and 18.379 , respectively. The peak at $R_{t}$ value 16.753 was found for aldrin. The peak of $\gamma$-chlordane and $\alpha$-chlordane were found at $R_{t}$ value 20.223 and 21.342. The peaks at $R_{t}$ value $21.925,25.065$ and 26.718 were found for endosulfan I, endosulfan II and endosulfan sulfate, respectively. The $\mathrm{R}_{\mathrm{t}}$ value of the peak of dieldrin was found at 23.154. The peaks 


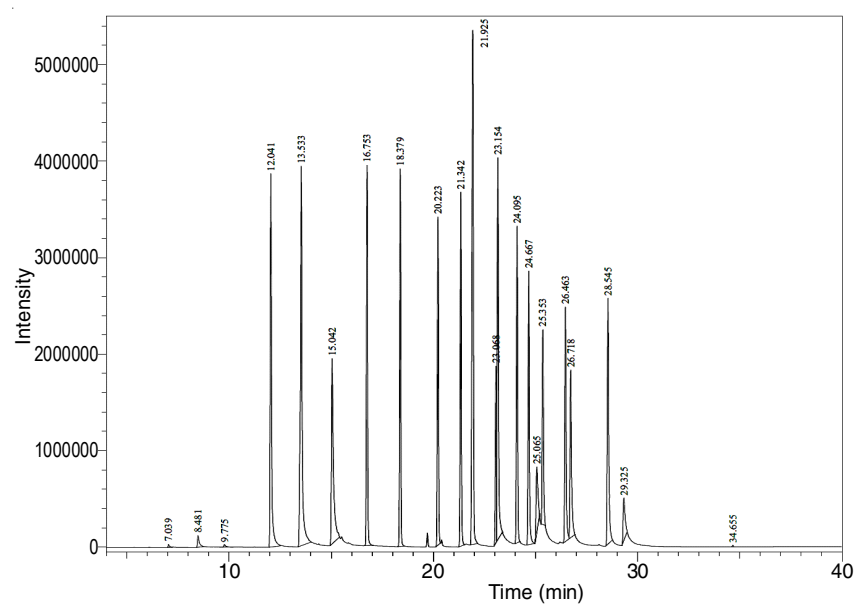

Fig. 1. Gas chromatogram of standards

at $R_{t}$ values $24.095,25.353$ and 29.325 correspond to endrin, endrin aldehyde and endrin ketone, respectively. The peaks of 4, $4^{\prime}$-DDE, 4,4'-DDD and 4,4'-DDT were found at $R_{t}$ values $23.068,24.667$ and 26.463 . The peak at $R_{t}$ value 28.545 was found for methoxychlor.

During the monitoring work chromatogram of pineapple (Fig. 2) exhibited number of peaks from those six peaks at the $\mathrm{R}_{\mathrm{t}}$ value 12.024, 13.522, 18.372, 23.139, 24.083 and 28.545 resemble with the $\mathrm{R}_{\mathrm{t}}$ values of $\beta$-BHC, $\delta$-BHC, heptachlor epoxide, dieldrin, endrin and methoxychlor respectively which indicated the presence of $\beta$-BHC, $\delta$-BHC, heptachlor epoxide, dieldrin, endrin and methoxychlor in pineapple.

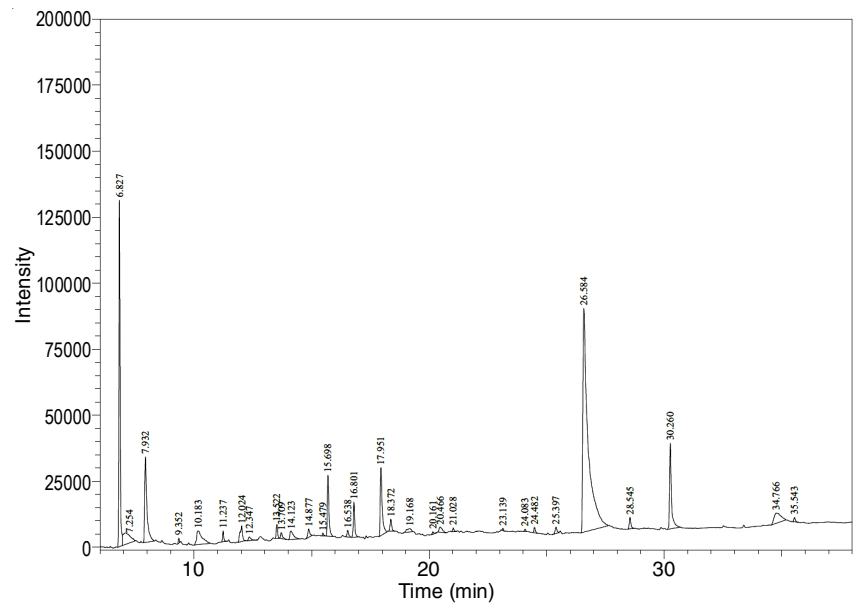

Fig. 2. Gas chromatogram of pineapple

The chromatogram of apple (Fig. 3) exhibited number of peaks from those seven peaks at $R_{t}$ value $9.771,13.523,18.374$, $23.135,24.081,25.046$ and 28.546 were very near to the $R_{t}$ value of $\gamma$-BHC, $\delta$-BHC, heptachlor epoxide, dieldrin, endrin, endosulfan II and methoxychlor respectively which indicated the presence of $\gamma$-BHC, $\delta$-BHC, heptachlor epoxide, dieldrin, endrin, endosulfan II and methoxychlor pesticides in apple.

In the chromatogram of plum (Fig. 4) eight peaks at $R_{t}$ value $9.765,12.023,13.520,18.361,23.067,24.080,26.725$ and 28.542 were very close to the $\mathrm{R}_{\mathrm{t}}$ value of $\gamma$-BHC, $\beta$-BHC, $\delta$-BHC, heptachlor epoxide, 4,4'-DDE, endrin, endosulfan sulfate and methoxychlor respectively which indicated the presence of above pesticides in plum.

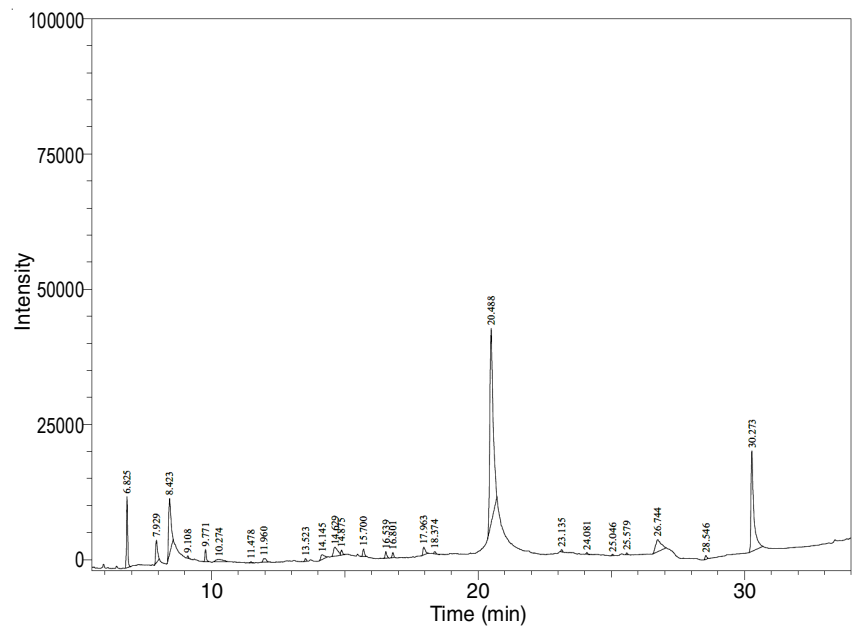

Fig. 3. Gas chromatogram of apple

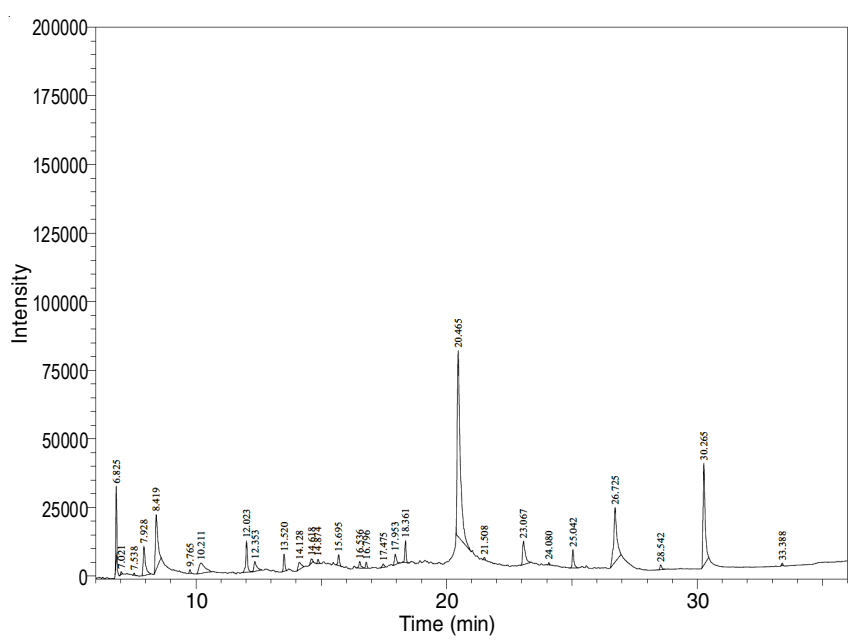

Fig. 4. Gas chromatogram of plum

The chromatogram of papaya (Fig. 5) exhibited a number of peaks from those eight peaks at the $\mathrm{R}_{\mathrm{t}}$ value $9.765,12.021$, 13.518, 18.361, 23.060, 24.079, 26.707 and 28.544 resemble with the $\mathrm{R}_{\mathrm{t}}$ value of $\gamma$-BHC, $\beta$-BHC, $\delta$-BHC, heptachlor epoxide, $4,4^{\prime}$-DDE, endrin, endosulfan sulfate and methoxychlor respectively, which indicated the presence of $\gamma$-BHC, $\beta$-BHC, $\delta$-BHC, heptachlor epoxide, 4,4'-DDE, endrin, endosulfan sulfate and methoxychlor pesticide in papaya.

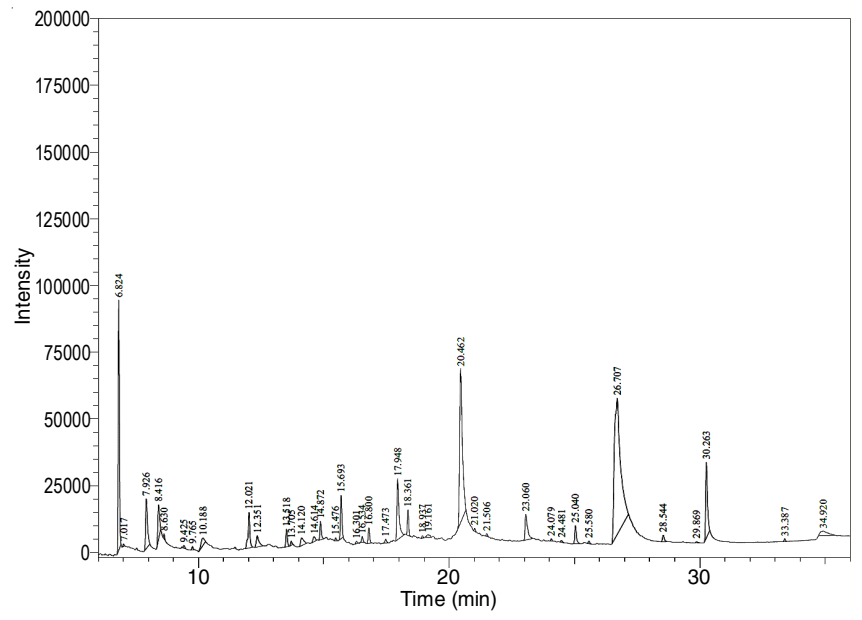

Fig. 5. Gas chromatogram of papaya 
In the chromatogram of mango (Fig. 6) six peaks at $\mathrm{R}_{\mathrm{t}}$ value $12.022,13.518,23.055,24.078,26.706$ and 28.540 were very near to the $\mathrm{R}_{\mathrm{t}}$ value of $\beta$-BHC, $\delta$-BHC, 4,4'-DDE, endrin, endosulfan sulfate and methoxychlor respectively, which indicated the presence of above pesticides in mango. The concentrations of detected pesticides have been reported in Table- 2 .

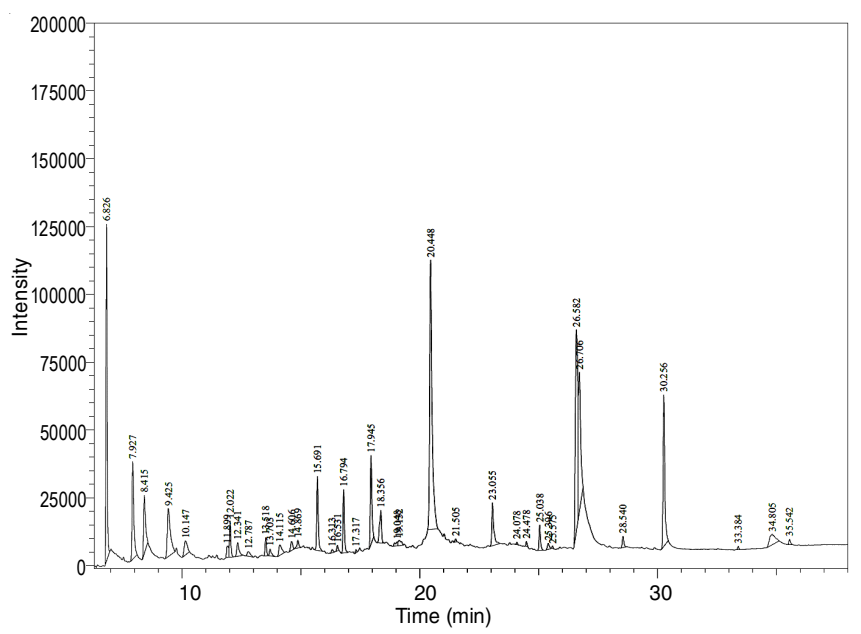

Fig. 6. Gas chromatogram of mango

\begin{tabular}{|c|c|c|c|c|}
\hline \multicolumn{5}{|c|}{$\begin{array}{c}\text { TABLE-2 } \\
\text { CONCENTRATION OF PESTICID }\end{array}$} \\
\hline $\begin{array}{l}\text { Name } \\
\text { of } \\
\text { sample }\end{array}$ & $\begin{array}{c}\text { RT } \\
\text { value }\end{array}$ & $\begin{array}{c}\text { Area of } \\
\text { peak }\end{array}$ & $\begin{array}{l}\text { Conc. of } \\
\text { pesticides } \\
(\mu \mathrm{g})\end{array}$ & $\begin{array}{l}\text { Name of the } \\
\text { pesticides }\end{array}$ \\
\hline \multirow{6}{*}{$\begin{array}{l}\frac{0}{0} \\
\frac{0}{0} \\
\stackrel{\Xi}{\Xi} \\
\vdots\end{array}$} & 12.024 & 42780 & 0.00096 & $\beta-\mathrm{BHC}$ \\
\hline & 13.522 & 21351 & 0.00036 & $\delta$-BHC \\
\hline & 18.372 & 22865 & 0.00060 & Heptachlor epoxide \\
\hline & 23.139 & 2861 & 0.00006 & Dieldrin \\
\hline & 24.083 & 3023 & 0.00009 & Endrin \\
\hline & 28.545 & 21199 & 0.00065 & Methoxychlor \\
\hline \multirow{7}{*}{$\frac{\frac{0}{2}}{\frac{2}{2}}$} & 9.771 & 8345 & 0.01870 & $\gamma$-BHC \\
\hline & 13.523 & 2184 & 0.00003 & $\delta$-BHC \\
\hline & 18.374 & 1909 & 0.00005 & Heptachlor epoxide \\
\hline & 23.135 & 1632 & 0.00003 & Dieldrin \\
\hline & 24.081 & 1166 & 0.00003 & Endrin \\
\hline & 25.046 & 998 & 0.00009 & Endosulfan II \\
\hline & 28.546 & 3187 & 0.00009 & Methoxychlor \\
\hline \multirow{8}{*}{$\stackrel{\Xi}{\Xi}$} & 9.765 & 5270 & 0.01181 & $\gamma$-BHC \\
\hline & 12.023 & 54455 & 0.00122 & $\beta-\mathrm{BHC}$ \\
\hline & 13.520 & 25470 & 0.00043 & $\delta$-BHC \\
\hline & 18.361 & 28926 & 0.00076 & Heptachlor epoxide \\
\hline & 23.067 & 63036 & 0.00361 & $4,4^{\prime}-\mathrm{DDE}$ \\
\hline & 24.080 & 2330 & 0.00007 & Endrin \\
\hline & 26.725 & 172138 & 0.00765 & Endosulfan sulfate \\
\hline & 28.542 & 8742 & 0.00026 & Methoxychlor \\
\hline \multirow{8}{*}{ 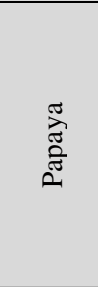 } & 9.765 & 4697 & 0.01053 & $\gamma$-BHC \\
\hline & 12.021 & 67223 & 0.00151 & $\beta-\mathrm{BHC}$ \\
\hline & 13.518 & 27315 & 0.00047 & $\delta$-BHC \\
\hline & 18.361 & 34347 & 0.00091 & Heptachlor epoxide \\
\hline & 23.060 & 65544 & 0.00375 & $4,4^{\prime}-\mathrm{DDE}$ \\
\hline & 24.079 & 2995 & 0.00009 & Endrin \\
\hline & 26.707 & 865959 & 0.03853 & Endosulfan sulfate \\
\hline & 28.544 & 12652 & 0.00038 & Methoxychlor \\
\hline \multirow{6}{*}{ 㳴 } & 12.022 & 53251 & 0.00119 & $\beta-\mathrm{BHC}$ \\
\hline & 13.518 & 26612 & 0.00045 & $\delta$-BHC \\
\hline & 23.055 & 90543 & 0.00519 & 4,4'-DDE \\
\hline & 24.078 & 3097 & 0.00009 & Endrin \\
\hline & 26.706 & 346059 & 0.01539 & Endosulfan sulfate \\
\hline & 28.540 & 19238 & 0.00059 & Methoxychlor \\
\hline
\end{tabular}

\section{ACKNOWLEDGEMENTS}

The authors are thankful to The Head, Advanced Instrumentation Research Facility Jawaharlal Nehru University, New Delhi, India for providing gas chromatography analysis.

\section{CONFLICT OF INTEREST}

The authors declare that there is no conflict of interests regarding the publication of this article.

\section{REFERENCES}

1. C. Kaur and H.C. Kapoor, Int. J. Food Sci. Technol., 36, 703 (2001); https://doi.org/10.1046/j.1365-2621.2001.00513.x.

2. Ministry of Agriculture \& Farmer Welfare, Horticulture Statistics at a Glance, Government of India (2017).

3. P.I. Devi, J. Thomas and R.K. Raju, Agric. Econ. Res. Rev., 30, 163 (2017).

4. R.M. Burkul, S.V. Ranade and B.L. Pangarkar, Int. J. Emerg. Trend Eng. Basic Sci., 2, 88 (2015).

5. I. Mahmood, S.R. Imadi, K. Shazadi, A. Gul and K.R. Hakeem, Effects of Pesticides on Environment, In: Plant, Soil and Microbes: Vol. 1 Implications in Crop Science, Springer International Publishing: Switzerland, p. 253 (2016).

6. S. Chandra, N.A. Mahindrakar, M. Kumar and P.L. Shinde, Int. J. Adv. Res., 2, 1075 (2014).

7. http://www.pan-uk.org/health-effects-of-pesticides/ (visited on 15/02/2019).

8. S.M. Bradberry, S.A. Cage, A.T. Proudfoot and J.A. Vale, Toxicol. Rev., 24, 93 (2005);

https://doi.org/10.2165/00139709-200524020-00003.

9. C.L. Beseler and L. Stallones, J. Agric. Saf. Health, 15, 327 (2009); https://doi.org/10.13031/2013.28887.

10. R. Sapbamrer and S. Nata, Environ. Health Prev. Med., 19, 12 (2014); https://doi.org/10.1007/s12199-013-0349-3.

11. A.A. Adewunmi and S.O. Fapohunda, Eur. J. Biol. Res., 8, 70 (2018); https://doi.org/10.5281/zenodo.1237542.

12. N. Tarannum, M. Singh and R. Hawaldar, Pesticides as an Occupational Hazard Facts and Figures, In: Handbook of Research on the Adverse Effects of Pesticide Pollution in Aquatic Ecosystems, IGI Global, p. 201 (2019).

13. M.C. Keifer and J. Firestone, J. Agromed., 12, 17 (2007); https://doi.org/10.1300/J096v12n01_03.

14. A.K. Srivastava and C. Kesavachandran, Health Effects of Pesticides, CRC Press (2019)

15. J.E. Jäger, Residues of Pesticides, In: Chemical Hazards in Foods of Animal Origin, Academic Publishers: Wageningen, p. 567 (2019).

16. D.P. Mukherjee, B. Kumar, S. Kumar, M. Mishra, R. Gaur, D. Prakash, S.K. Singh and C.S. Sharma, Arch. Appl. Sci. Res., 3, 85 (2011).

17. R.K. Kole, H. Banerjee and A. Bhattacharyya, Bull. Environ. Contam. Toxicol., 67, 554 (2001); https://doi.org/10.1007/s001280159.

18. L. Guzzella, C. Roscioli, L. Viganò, M. Saha, S.K. Sarkar and A. Bhattacharya, Environ. Int., 31, 523 (2005);

https://doi.org/10.1016/j.envint.2004.10.014.

19. L. Saunders, P. Kadhel, N. Costet, F. Rouget, C. Monfort, J.P. Thome, L. Guldner, S. Cordier and L. Multigner, Environ. Int., 68, 171 (2014); https://doi.org/10.1016/j.envint.2014.03.024.

20. K.-S. Kim, Y.-M. Lee, S.G. Kim, I.-K. Lee, H.-J. Lee, J.-H. Kim, J. Kim, H.-B. Moon, D.R. Jacobs Jr. and D.-H. Lee, Chemosphere, 94, 151 (2014); https://doi.org/10.1016/j.chemosphere.2013.09.066.

21. K.P. Singh, A. Malik, D. Mohan and S. Sinha, Bull. Environ. Contam. Toxicol., 74, 162 (2005); https://doi.org/10.1007/s00128-004-0563-1.

22. T. Vial, B. Nicolas and J. Descotes, J. Toxicol. Environ. Health, 48, 215 (1996); https://doi.org/10.1080/009841096161294.

23. S.H. Safe, Environ. Health Perspect., 103, 346 (1995); https://doi.org/10.1289/ehp.95103346.

24. C. Beseler, L. Stallones, J.A. Hoppin, M.C. Alavanja, A. Blair, T. Keefe and F. Kamel, J. Occup. Environ. Med., 48, 1005 (2006); https://doi.org/10.1097/01.jom.0000235938.70212.dd.

25. E. Sohail, A. Waseem, W.L. Chae, J.L. Jong and H. Imitiaz, J. Clin. Exp. Oncol., 26, 98 (2004).

26. D. Kumar and A. Kashyap, J. Chem. Pharm. Res., 6, 751 (2014).

27. D. Kumar and P. Kulshrestha, J. Chem. Pharm. Res., 8, 539 (2016). 